\title{
A Comparative Study on Modified Johnson-Cook and Arrhenius-Type Constitutive Models to Predict the Hot Deformation Behaviour of Molybdenum-Hafnium-Carbide Alloy
}

\author{
Athar Safari, Muhammad Imran, and Sabine Weiss
}

Submitted: 26 June 2020 / Revised: 3 December 2020 / Accepted: 29 December 2020 / Published online: 9 February 2021

\begin{abstract}
Molybdenum alloys are commonly used as tool material for high-temperature deformation processes like forming or forging. For these types of application, the material has to withstand static load at elevated temperatures. To investigate the high-temperature performance of the material, uniaxial hot tensile tests were performed on a Mo-1.2\% Hf-0.1\% C alloy (MHC) over the temperature range of 1173-1473 K with intervals of $100 \mathrm{~K}$ and strain rates of $0.001,0.01$ and $0.1 \mathrm{~s}^{-1}$ up to the fracture of the specimen. The flow stress decreases with increase in temperature and the reduction in strain rate. This behaviour could be related to the increasing rate of restoration mechanisms, i.e. dynamic recrystallization or recovery as well as to the decrease in the strain hardening rate. Microstructure of the two most critical hot deformation conditions were shown and compared. Based on modified Johnson-Cook and strain-compensated Arrhenius-type models, constitutive equations were established to predict the high-temperature flow stress of the respective MHC alloy. The accuracy of both models was evaluated by comparing the predicted stress values and the values obtained from experiments. Correlation coefficient, average absolute relative error, the number of material constants involved and the computational time required for evaluating the constants were calculated to quantify and compare the precision of both models. The flow stress values predicted by the constitutive equations are in good agreement with the experimental results. At lower strain rates $(0.001$ and $0.01 \mathrm{~s}^{-1}$ ), distinct deviation from the experimental results can be observed for the modified JohnsonCook model. Despite the longer evaluation time and the larger number of material constants, the deformation behaviour, tracked by the Arrhenius-type model is more accurate throughout the entire deformation process.
\end{abstract}

Keywords constitutive equation, flow stress, hot tensile deformation, molybdenum-hafnium-carbide alloy (MHC)

\section{Introduction}

Molybdenum (Mo) is a refractory metal that retains its bodycentred cubic (bcc) crystal structure from room temperature up to its very high melting temperature of $2610^{\circ} \mathrm{C}$. Alloys based on Mo present high creep resistance, high thermal stability and thermal conductivity. Therefore, they are very notable for many important high-temperature applications (e.g. crucial components in turbines, missiles and fusion reactors) (Ref 1, 2). The major disincentive against performance of Mo as a hightemperature structural material is related to its weak strength at temperatures above $0.5 T_{\mathrm{m}}$. Among different methods to increase the strength of refractory metals subjected to high temperature, dispersion strengthening is found to be a very

Athar Safari and Sabine Weiss, Metallurgy and Materials Technology, Brandenburg University of Technology CottbusSenftenberg, Cottbus, Germany; and Muhammad Imran, Brandenburg University of Technology Cottbus-Senftenberg, Cottbus, Germany. Contact e-mail: athar.safarialadolat@b-tu.de. effective one. Hafnium carbide (HfC), a compound with a $\mathrm{NaCI}$ structure and the highest melting temperature $\left(3890{ }^{\circ} \mathrm{C}\right)$ among all carbides, is an ideal particle hardener for Mo, resulting in socalled molybdenum-hafnium-carbide alloy (Ref 3, 4).

Hot deformation is an essential way not only to reach a fundamental understanding of the flow behaviour of materials at forming temperatures and strain rates, but also to determine the optimum conditions for industrial processing ( $\operatorname{Ref} 5,6)$. The temperature range is chosen based on the melting point of the material (Ref 7). In order to cover the strain rates used in most of the industrial processing rates, the selected strain rate range usually spans from $10^{-3}$ to $10^{2} \mathrm{~s}^{-1}$. Most of the previous studies analysing the hot deformation behaviour of Mo and its alloys are based on compression tests (Ref 7-11). Chaudhuri et al. investigated the deformation behaviour of Mo-TZM between 1400 and $1700{ }^{\circ} \mathrm{C}$ and in a strain rate range of $10^{3}$ $10 \mathrm{~s}^{-1}$. The microstructural evolution during deformation with focus on dynamic recovery and recrystallization has been extensively explained (Ref 9). Xia et al. (Ref 10) investigated the effects of high-temperature deformation on microstructure and texture as well as the evolution of microstructure under different strain of pure Mo. Using a sintered plate with a random texture as a starting material, Primig et al. (Ref 8) studied the microstructural mechanisms of pure Mo. The uniaxial tension behaviour and the microstructure evolution of wrought molybdenum at different temperatures have been investigated by Fang et al. (Ref 12). Using in situ SEM 
observations, the dominant fracture mechanism has been characterized as cleavage at lower temperatures and as a mixture of cleavage and plastic shear at higher temperatures. In a study by Alur et al., microstructural evolution during compression deformation of a two-phase (Mo solid solution + T2 phase $\left(\mathrm{Mo}_{5} \mathrm{SiB}_{2}\right)$ ) Mo-6.1Si-7.9B (at.\%) alloy has been examined with respect to strain rate changes within the 1000 $1400{ }^{\circ} \mathrm{C}$ range and compared to that of commercially available powder metallurgy processed TZM. Finite element analysis has been used to simulate compressive deformation behaviour in two-phase Mo-Si-B alloys (Ref 13).

The constitutive equation, as the mathematical representation of the deformation behaviour of materials, has been used as input to the finite element simulation code of the material under specified loading conditions or to develop a reasonable processing technology (Ref 14). Up to now, the constitutive model developed for Mo alloys is mostly based on hot compression experiments (Ref 11, 15-19). Wang et al. established the constitutive equation for pure Mo based on stress-strain curves and the hyperbolic sine model with Zener-Hollomon using hot compression tests (Ref 11). A constitutive model proposed by Cheng and Nemat-Nasser has been extended to explain both the dynamic and the quasistatic stress-strain response of a commercially pure molybdenum within the temperature range $27-827^{\circ} \mathrm{C}$ (Ref 20). Schimpf et al. have analysed the mechanical behaviour of Mo-TZM based on strain rate jump tests and using the constitutive equations according to the theory of Seeger (Ref 21). Only few studies have been carried out based on hot tensile tests. The constitutive equation of molybdenum sheet via uniaxial tensile tests in hot environment has been studied by Meng (Ref 22).

The selection of the experimental methodology was based on the application of the investigated material which is mainly used for forging tools. For prediction of the tool life, it is required to know the fracture behaviour of the material. Since the compression test cannot provide any information about the specimen fracture, hot tensile tests were selected for the current work. Another reason for the realization of tensile tests was the formation of voids or cracks under positive stress triaxiality. Even in compression tests, cracks appear in the region of local, positive stress triaxiality, i.e. on the outer surface of the bulging region. However, such cracks cannot lead to specimen fracture. The true behaviour of crack formation leading to material failure can only be achieved in positive stress state occurring during tensile tests.

Among numerous models, the hyperbolic sine Arrheniustype constitutive model has been widely applied to predict the high-temperature flow behaviour of various materials. It was originally proposed by Sellars and McTegart (Ref 23) and has been rectified several times to appropriately represent the elevated temperature flow behaviour of different alloys. A modified Johnson-Cook model which was successfully incorporated in finite element analysis packages for high-strength alloys has also been widely used in recent years (Ref 24).

Development of constitutive equations based on tensile experiments is barely carried out. Moreover, the hot deformation behaviour of $\mathrm{MHC}$ as an ideal material for critical applications is insufficiently studied. Therefore, the aim of this study is to develop constitutive equations based on two improved models and modified Johnson-Cook and Arrhenius-type to present a comparative analysis on their capability to predict the elevated temperature flow behaviour of $\mathrm{MHC}$ material using uniaxial tensile tests in a certain range of temperature and strain rate.

\section{Material and Methods}

The starting material for the current investigation was a forged rod of MHC, processed by powder metallurgy, provided by Plansee, Austria. The chemical composition of this alloy is Mo- $1.2 \%$ Hf- $0.1 \%$ C. Cylindrical tensile specimen with dimensions shown in Fig. 1 was machined from the as-build rods. The specimen geometry is adopted according to the standard specimen design provided by the testing system. The sharp edges on the left and right side of the specimen are required to avoid any gap between the specimen shaft and the outer wall of the clamp. The sharp transition of the cross section is also required from the shaft to gauge section which allows the positioning of the rods for measuring the change in gauge length. Uniaxial tensile tests at temperatures ranging from 900 to $1200{ }^{\circ} \mathrm{C}$ in intervals of $100{ }^{\circ} \mathrm{C}$ and with strain rates of 0.001 , 0.01 and $0.1 \mathrm{~s}^{-1}$ were performed using deformation dilatometer DIL805A/D/T from TA instruments (New Castle, Germany). The specimens were heated with a heating rate of $10 \mathrm{~K} / \mathrm{s}$ and held for 5 min to obtain a homogeneous temperature distribution through the specimens before tensile testing. The specimens were elongated until fracture and then cooled down immediately to room temperature using helium gas cooling. Load change and length change were automatically recorded and subsequently transformed to the true stress-strain curves. To reproduce the experimental results, each test is repeated twice, and an average value is calculated. In order to protect the specimen and the machine from severe surface damage caused by oxidation, the tests were conducted in vacuum of $10^{-4}$ mbar. The samples deformd at $900{ }^{\circ} \mathrm{C}$ and $1200{ }^{\circ} \mathrm{C}$ and strain rate of $0.001 \mathrm{~s}^{-1}$ were prepared for microstructural observation. They were vapor-deposited with a thin layer of gold before they were electroplated with an approx. $80 \mu \mathrm{m}$ copper layer. Grinding and polishing were then performed in several stages after embedding the samples with a conductive resin. For the finish, the samples were placed in the vibration polisher for a short time. The EBSD measurements were performed using a TESCAN Mira II scanning electron microscope (SEM) (Brno, Czech Republic) and an EDAX EBSD system (TSL OIM Data Collect and TSL OIM Analysis, version 7.4) (Mahwah, NJ, USA). The following parameters were applied for the measurements: tilting angle of $70^{\circ}$, acceleration voltage of $20 \mathrm{kV}$, step size of $0.2 \mu \mathrm{m}$, and working distance of $19-23 \mathrm{~mm}$.

\section{Results and Discussion}

\subsection{Stress-Strain Curves}

Typical true stress-true strain curves from the uniaxial tensile tests of MHC alloy, obtained at 900, 1000, 1100 and $1200{ }^{\circ} \mathrm{C}$ with strain rates of $0.001,0.01$ and $0.1 \mathrm{~s}^{-1}$, respectively, are presented in Fig. 2(a)-(d). The flow stress values are affected by deformation temperatures and strain rates. In general, the flow stress rises with increasing strain rate while keeping the temperature constant, whereas the flow stress declines with increasing temperature for constant strain rate. A fast increase in the flow curves due to the rapid accumulation of 


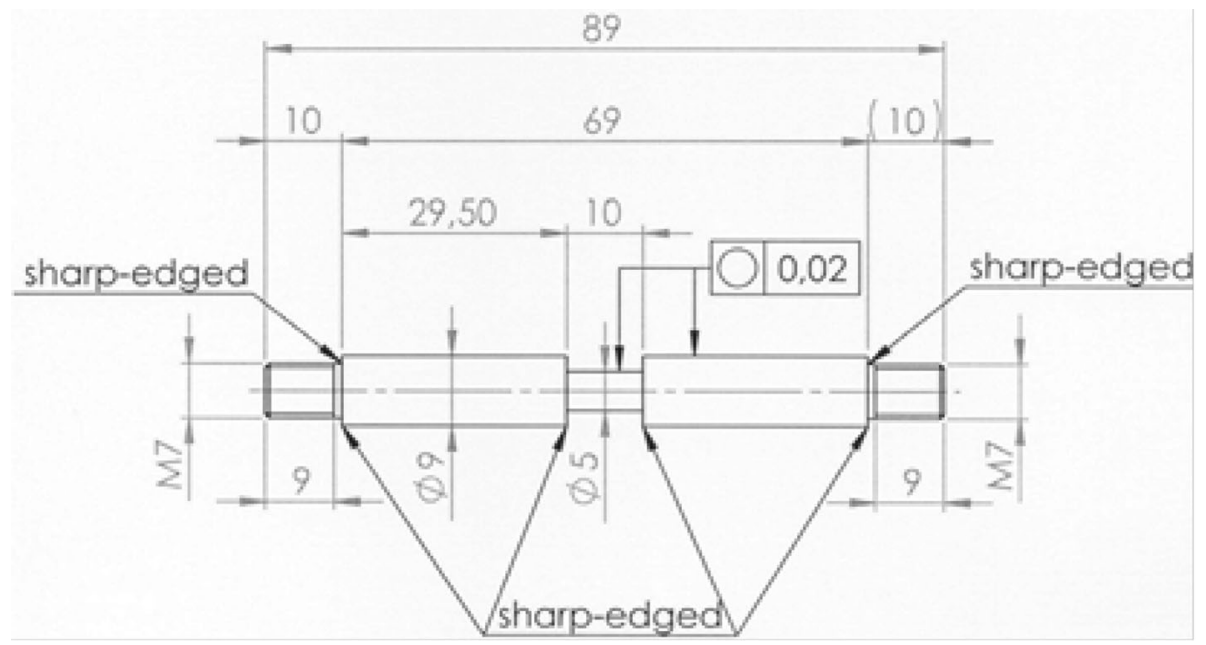

Fig. 1 Geometry of the tensile test sample
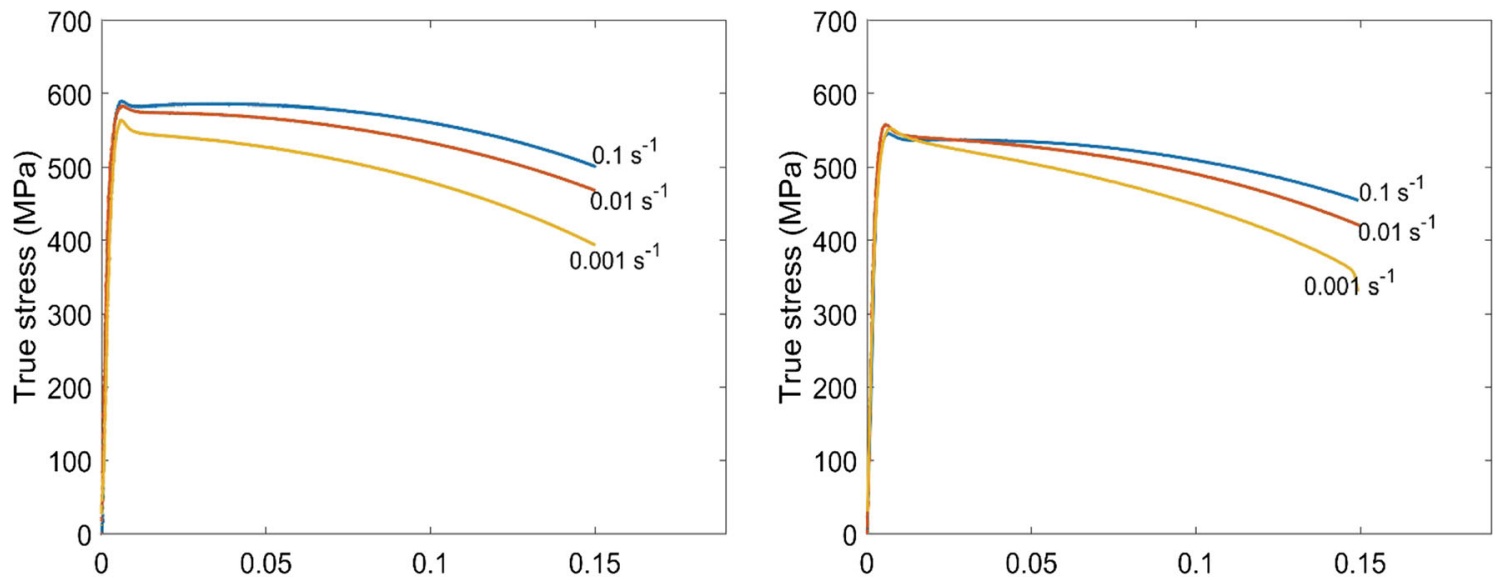

(a) $-1173 \mathrm{~K}$

(b)-1273 K

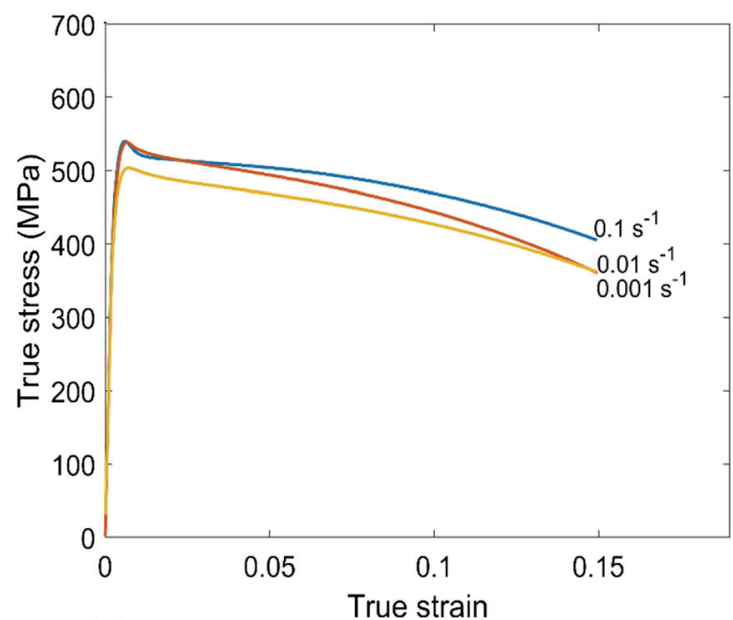

(c) $-1373 \mathrm{~K}$

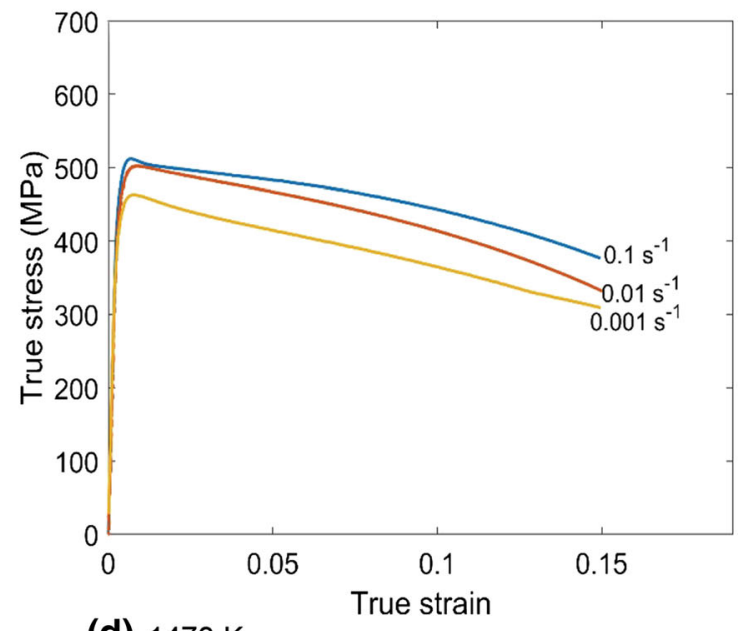

(d) $-1473 \mathrm{~K}$

Fig. 2 True stress-true strain curves of MHC molybdenum alloy obtained by uniaxial tensile test at different strain rate and temperature: (a) $1173 \mathrm{~K}$, (b) $1273 \mathrm{~K}$, (c) $1373 \mathrm{~K}$ and (d) $1473 \mathrm{~K}$

dislocations can be observed for all temperatures and strain rates, followed by a reduction to some degree after reaching the maximum, indicating thermal softening. For the higher temperature and the lower strain rate (i.e. $1200{ }^{\circ} \mathrm{C}$ and $0.001 \mathrm{~s}^{-1}$ ), transient flow softening behaviour is more pronounced, which can be attributed to the increase in restoration mechanisms (i.e. dynamic recrystallization), the decrease in strain hardening rate or to the adiabatic heating generated during deformation (Ref 9, 
25, 26). The peak stress at $0.1 \mathrm{~s}^{-1}$ is approx. $10 \mathrm{MPa}$ less than that at strain rates of 0.01 and $0.001 \mathrm{~s}^{-1}$ which leads to a difference of less than $2 \%$. The peak stress appears at a very low strain of approx 0.01 . Such a small difference in peak stress at low strain can be due to the heterogeneous nature of the grain size distribution. Even the probability of slightly larger grain size than the average grain size in the gauge section can be the reason for such a small difference in peak stress at high strain rate as compared to higher stress at lower strain rates.

\subsection{Microstructure Analysis}

The microstructure of the samples was investigated by means of scanning electron microscopy (SEM) in combination with electron backscatter diffraction (EBSD) technique. Figure 3 represents the inverse pole figure (IPF) map of the initial forged MHC before deformation.

The inverse pole figure maps of the initial state show a homogeneous fine grained microstructure with approximately 1 micrometre grain diameter and weak preference for $\{111\}$ orientation. The two most critical conditions after hot deformation have been selected to show the changes in grain size distribution during hot deformation. Figure 4 displays the invers pole figure (IPF) mappings of deformed $\mathrm{MHC}$ at temperatures of (a) $900{ }^{\circ} \mathrm{C}$ and (b) $1200{ }^{\circ} \mathrm{C}$ and strain rates of $0.001 \mathrm{~s}^{-1}$. Strong elongation of the grains took place during both deformation processes, but at $900{ }^{\circ} \mathrm{C}$ dynamic recovery is the more significant softening mechanism, since the micrograph is mostly consisted of elongated grains with larger in-grain misorientation and without significant orientation changes with respect to the initial texture. On the other hand, after deformation at $1200{ }^{\circ} \mathrm{C}$, a larger area consisted of fine equiaxed grains with different orientation changes with respect to the initial texture is observed which is prominent indication for dynamic recovery. Deformation at higher temperatures promotes easier slip and climbing of dislocations which results in the formation of nuclei for dynamic recrystallization (Ref 15).

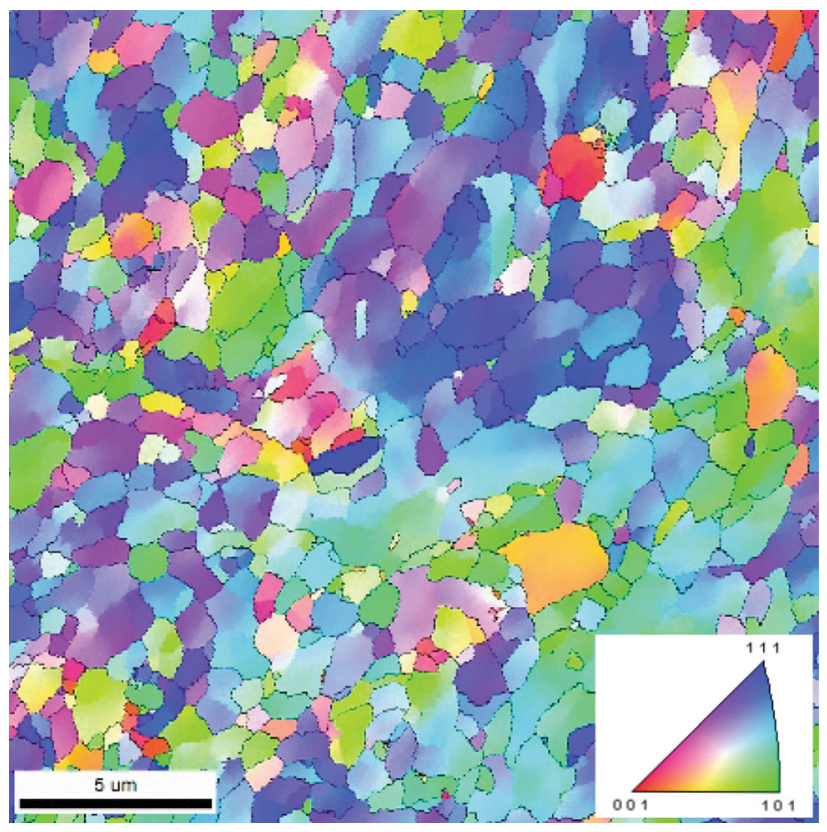

Fig. 3 Inverse pole figure maps of the initial microstructure
The more steady-state flow curve at $900{ }^{\circ} \mathrm{C}$ and strain rate of $0.1 \mathrm{~s}^{-1}$ could be a sign of increasing DRV (Ref 27).

\subsection{Modified Johnson-Cook Model}

The modified Johnson-Cook model considers the coupled effects of temperature and strain rate on the flow behaviours and is represented as:

$\sigma=\left(A_{1}+B_{1} \varepsilon+B_{2} \varepsilon^{2}\right)\left(1+C_{1} \ln \dot{\varepsilon}^{*}\right) \exp \left[\left(\lambda_{1}+\lambda_{2} \ln \dot{\varepsilon}^{*}\right) T^{*}\right]$

where $\sigma$ is the equivalent flow stress in $\mathrm{MPa}, \varepsilon$ is the equivalent plastic strain, $A_{1}, B_{1}, B_{2}, C_{1}, \lambda_{1}, \lambda_{2}$ are material constants, $\dot{\varepsilon}^{*}=\dot{\varepsilon} / \dot{\varepsilon}_{0}$ is the dimensionless strain rate $(\dot{\varepsilon}$ is the strain rate, and $\dot{\varepsilon}_{0}$ is the reference strain rate), and $T^{*}$ is the homologous temperature and expressed as $T^{*}=T-T_{0}$ ( $T$ is the current, and $T_{0}$ is the reference temperatures).

$1173 \mathrm{~K}$ is taken as reference temperature $\left(T_{0}\right)$ and $0.01 \mathrm{~s}^{-1}$ as reference strain rate $\left(\dot{\varepsilon}_{0}\right)$, in order to obtain the material constants of the modified Johnson-Cook model.

At the deformation temperature of $1173 \mathrm{~K}$ and the strain rate of $0.01 \mathrm{~s}^{-1}$, Eq 1 can be expressed as:

$\sigma=\left(A_{1}+B_{1} \varepsilon+B_{2} \varepsilon^{2}\right)$

Substituting the corresponding flow stress values into Eq 2, the relationship between $\sigma$ and $\varepsilon$ can be obtained in a secondorder polynomial as shown in Fig. 5. The fitting of the polynomial functions resulted in the values of $A_{1}, B_{1}$ and $B_{2}$ as $578.28,31.13$ and -4932.4 , respectively.

When the deformation temperature is $1173 \mathrm{~K}, \mathrm{Eq} 1$ can expressed as:

$\frac{\sigma}{\left(A_{1}+B_{1} \varepsilon+B_{2} \varepsilon^{2}\right)}=\left(1+C_{1} \ln \dot{\varepsilon}^{*}\right)$

Substituting the three different strain rates and the corresponding flow stress at different strain into $\mathrm{Eq} \mathrm{3}$, the relationship between $\frac{\sigma}{\left(A_{1}+B_{1} \varepsilon+B_{2} \varepsilon^{2}\right)}$ and $\ln \dot{\varepsilon}^{*}$ can be gained as shown in Fig. 6. Therefore, the value of $C_{1}$ can be evaluated by linear fitting method as the slope of the curve as 0.0258 .

Introducing a new parameter $\lambda$, which is expressed as:

$\lambda=\lambda_{1}+\lambda_{2} \ln \dot{\varepsilon}^{*}$

Equation 1 can be written as:

$\frac{\sigma}{\left(A_{1}+B_{1} \varepsilon+B_{2} \varepsilon^{2}\right)\left(1+C_{1} \ln \dot{\varepsilon}^{*}\right)}=e^{\lambda T^{*}}$

Taking the logarithm of both sides of Eq 5 gives,

$\ln \left\{\frac{\sigma}{\left(A_{1}+B_{1} \varepsilon+B_{2} \varepsilon^{2}\right)\left(1+C_{1} \ln \dot{\varepsilon}^{*}\right)}\right\}=\lambda T^{*}$

The mean values of $\ln \left\{\frac{\sigma}{\left(A_{1}+B_{1} \varepsilon+B_{2} \varepsilon^{2}\right)\left(1+C_{1} \ln \dot{\varepsilon}^{*}\right)}\right\}$ at different strains (0.006-0.14) are used to determine the values of $\lambda$. For different strain rates and deformation temperatures, the relationship between $\ln \left\{\frac{\sigma}{\left(A_{1}+B_{1} \varepsilon+B_{2} \varepsilon^{2}\right)\left(1+C_{1} \ln \dot{\varepsilon}^{*}\right)}\right\}$ and $T^{*}$ can be obtained. Then, the values of $\lambda$ for three different strain rates can be obtained from the slopes of the linear fitting curves. The parameter $\lambda$ is a function of strain rate, thus, $\lambda_{1}$ and $\lambda_{2}$ can be evaluated from the plot $\lambda$ versus $\ln \dot{\varepsilon}^{*}$ as the intercept ($0.00073)$ and slope $(0.0000217)$ respectively, as shown in Fig. 7. 

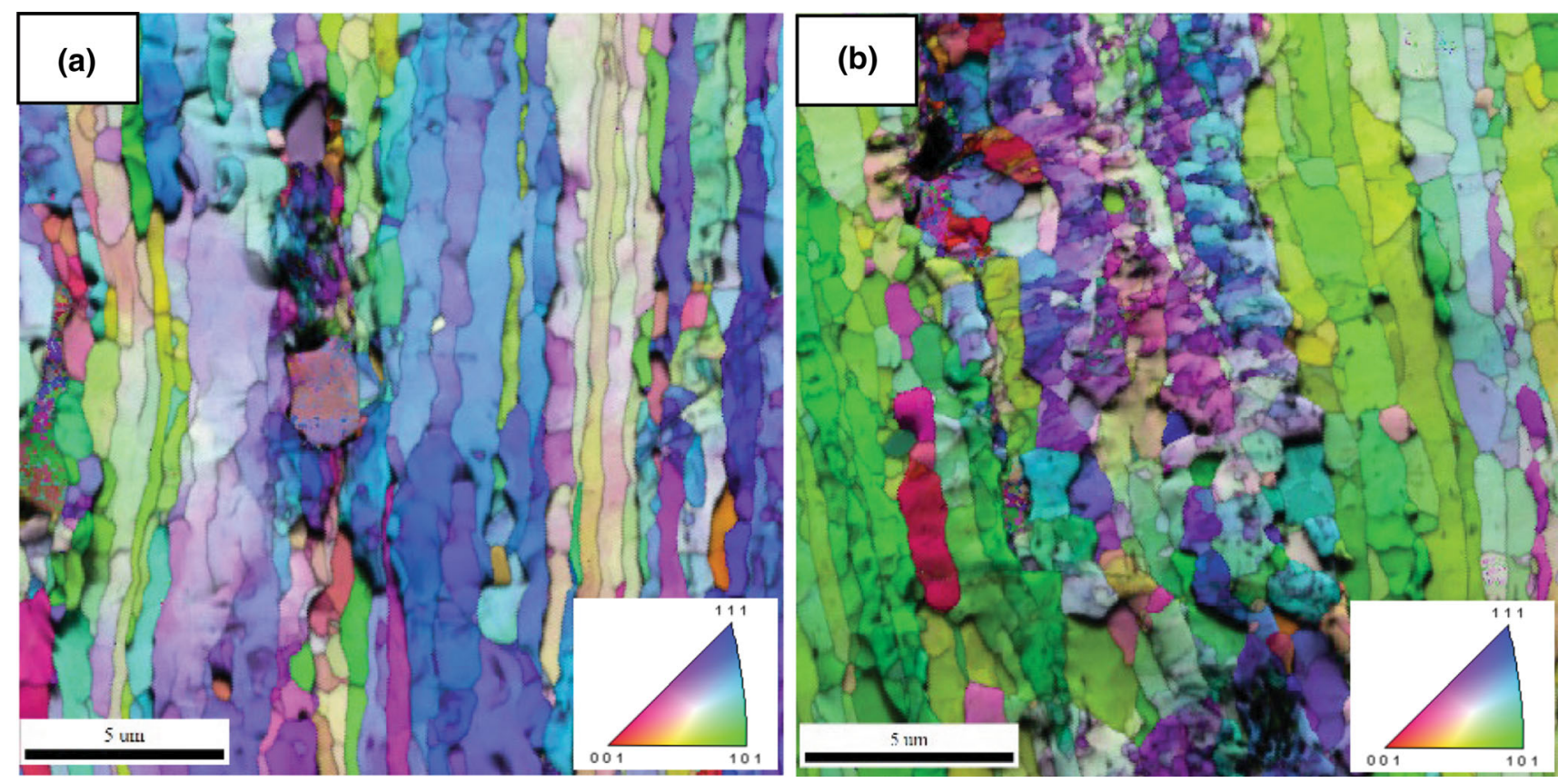

Fig. 4 Inverse pole figure maps of the deformed microstructure at different deformation conditions (a) $900{ }^{\circ} \mathrm{C}$ and strain rate of $0.001 \mathrm{~s}^{-1}$, (b) $1200{ }^{\circ} \mathrm{C}$ and strain rate of $0.001 \mathrm{~s}^{-1}$

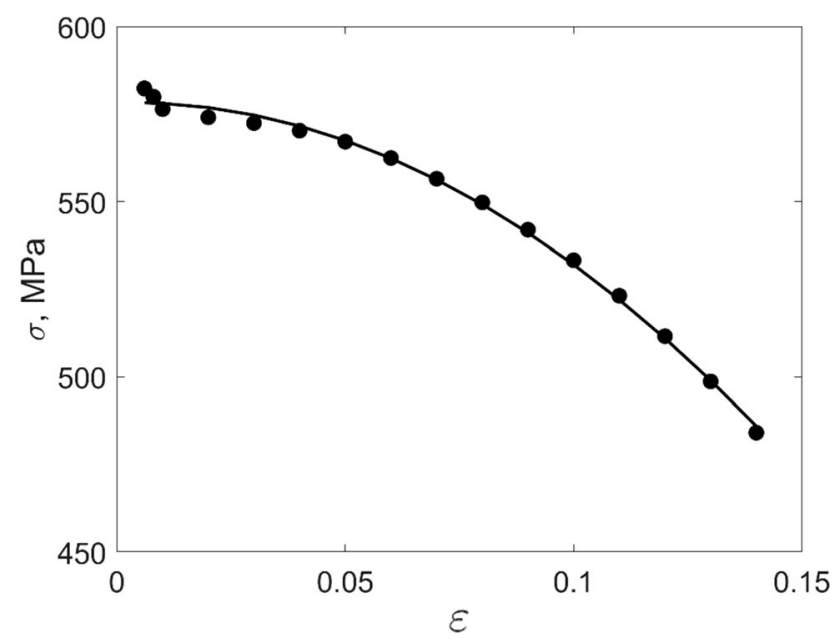

Fig. 5 Relationship between $\sigma$ and $\varepsilon$ at the temperature of $1173 \mathrm{~K}$ and strain rate of $0.01 \mathrm{~s}^{-1}$ in a second-order polynomial fit

The parameters of the modified Johnson-Cook model for MHC are provided in Table 1. The modified Johnson-Cook constitutive equation for MHC alloy can be obtained as:

$$
\begin{aligned}
\sigma= & \left(578.28+31.13 \varepsilon-4932.4 \varepsilon^{2}\right)\left(1+0.0258 \ln \dot{\varepsilon}^{*}\right) \\
& \exp \left[\left(-0.00073+0.0000217 \ln \dot{\varepsilon}^{*}\right) T^{*}\right]
\end{aligned}
$$

\subsection{Arrhenius-Type Constitutive Model}

The Zener-Hollomon parameter represents the combined effect of temperature and strain rate on the deformation behaviour of materials in an exponent-type equation. This socalled Arrhenius equation is widely used to explain the correlation between strain rate, flow stress and temperature,

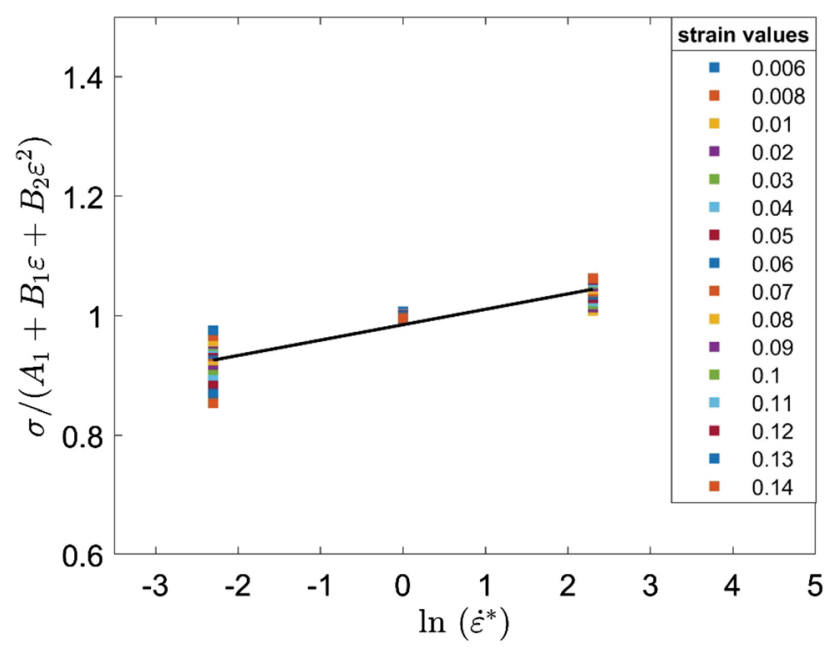

Fig. 6 Relationship between $\frac{\sigma}{\left(A_{1}+B_{1} \varepsilon+B_{2} \varepsilon^{2}\right)}$ and $\ln \dot{\varepsilon}^{*}$ at the temperature of $1173 \mathrm{~K}$

during hot deformation. These are represented in mathematical forms in $\mathrm{Eq} 8-11$ (Ref 22, 28-30).

$Z=\dot{\varepsilon} \exp \left(\frac{Q}{\mathrm{RT}}\right)$

$\dot{\varepsilon}=A_{1} \sigma^{n_{1}} \exp \left(-\frac{Q}{\mathrm{RT}}\right) \quad$ for $\quad \alpha \sigma<0.8$

$\dot{\varepsilon}=A_{2} \exp (\beta \sigma) \exp \left(-\frac{Q}{R T}\right)$ for $\quad \alpha \sigma>1.2$

$\dot{\varepsilon}=A[\sinh (\alpha \sigma)]^{n} \exp \left(-\frac{Q}{R T}\right)$ for all $\sigma$ 
wherein $Z$ is the Zener-Hollomon parameter $\left(\mathrm{s}^{-1}\right), Q$ is the activation energy of hot deformation $\left(\mathrm{kJ} \mathrm{mol}^{-1}\right), R$ is the universal gas constant $\left(8.314 \mathrm{~J} \mathrm{~mol}^{-1} \mathrm{~K}^{-1}\right), T$ is the deformation temperature $(\mathrm{K}), \dot{\varepsilon}$ is the strain rate $\left(\mathrm{s}^{-1}\right), \sigma$ is the flow stress for a given strain $(\mathrm{MPa})$ and $A, A_{1}, A_{2}, n_{1}, n, \alpha, \beta$ are the material constants, $\alpha\left(=\beta / n_{1}\right)$ is an adjustable constant $\left(\mathrm{MPa}^{-1}\right)$.

Since the flow stress values are altering with increasing strain, the effect of strain on the material constants in constitutive equation should be considered (Fig. 2). As an example, the strain of 0.08 is taken to introduce the solution procedures to calculate the material constants.

Taking natural logarithm of $\mathrm{Eq} \mathrm{9,10,12} \mathrm{and} 13$ can be derived.

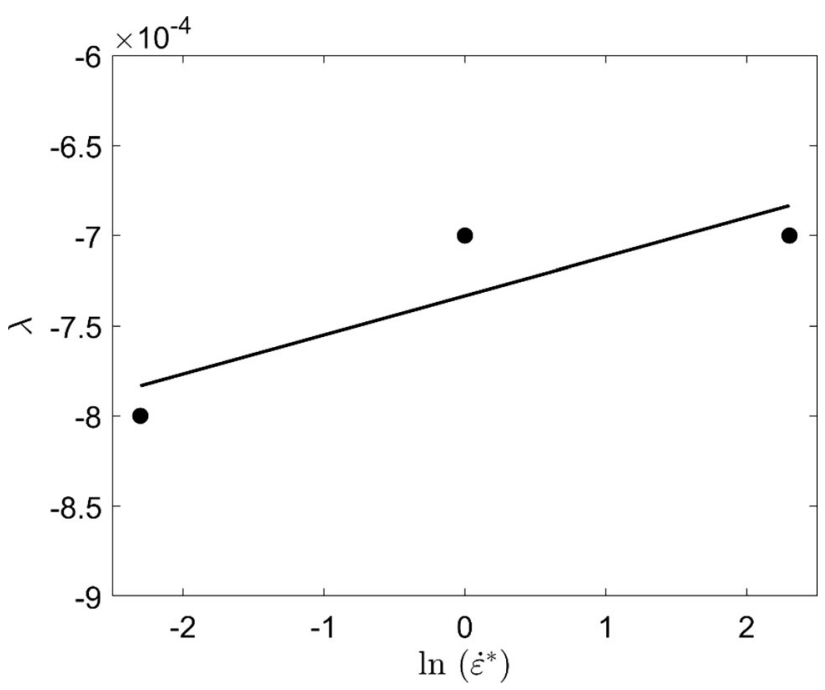

Fig. 7 Plot of $\lambda$ vs. $\ln \dot{\varepsilon}^{*}$

$\ln \dot{\varepsilon}=\ln A_{1}-\frac{Q}{\mathrm{RT}}+n_{1} \ln \sigma$

$\ln \dot{\varepsilon}=\ln A_{1}-\frac{Q}{\mathrm{RT}}+\beta \sigma$

At constant deformation temperature, taking partial differentiation of Eq 12 and 13 and substituting the values of the strain rate and corresponding flow stresses under the strain of 0.08 , gives the relationship between the flow stress and strain rate, as shown in Fig. 8(a) and (b). The values of $n_{1}$ and $\beta$ can be acquired from the slope of the parallel and straight lines in the $\ln \dot{\varepsilon}-\ln \sigma$ and $\ln \dot{\varepsilon}-\sigma$ plots, respectively. These lines are obtained by linear regression from where $n_{1}$ and $\beta$ can be computed for different temperatures. As the slopes of the fitting lines are approximately the same, the values of $n_{1}$ and $\beta$ can be computed for different temperatures by linear fitting method and the mean values of $n_{1}$ and $\beta$ are calculated to be 38.615 and $0.0805 \mathrm{MPa}^{-1}$, respectively.

Taking the natural logarithm of Eq 11, 14 can be derived.

$\ln \dot{\varepsilon}=\ln A-\frac{Q}{\mathrm{RT}}+n \ln [\sinh (\alpha \sigma)]$

Assuming that the activation energy is independent of temperature, at a given temperature, $\mathrm{n}$ can be expressed as:

$n=\left[\frac{\partial \ln \dot{\varepsilon}}{\partial \ln [\sinh (\alpha \sigma)]}\right]_{T}$

At a given strain rate, $Q$ can be expressed as:

$Q=R n\left[\frac{\partial \ln [\sinh (\alpha \sigma)]}{\partial T^{-1}}\right]_{\dot{\varepsilon}}$

Substituting Eq 8 into Eq 9, the value of $Q$ can be expressed as:

Table 1 Calculated parameters for the modified Johnson-Cook model

\begin{tabular}{lcccccc}
\hline Parameter & $\boldsymbol{A}_{\mathbf{1}}$ & $\boldsymbol{B}_{\mathbf{1}}$ & $\boldsymbol{B}_{\mathbf{2}}$ & $\boldsymbol{C}_{\mathbf{1}}$ & $\boldsymbol{\lambda}_{\mathbf{1}}$ & $\boldsymbol{\lambda}_{\mathbf{2}}$ \\
\hline Value & 578.28 & 31.13 & -4932.4 & 0.0258 & -0.00073
\end{tabular}
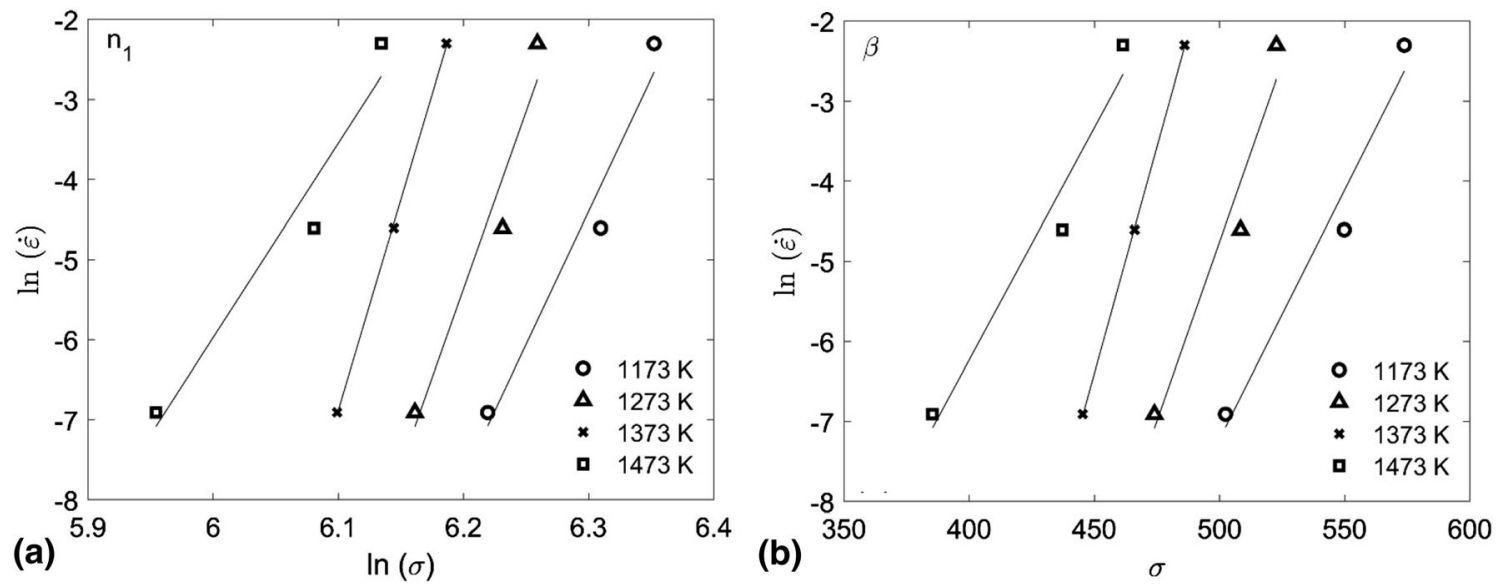

Fig. 8 Relationship between $\ln \dot{\varepsilon}$ and (a) $\ln \sigma$ and (b) $\sigma$ 


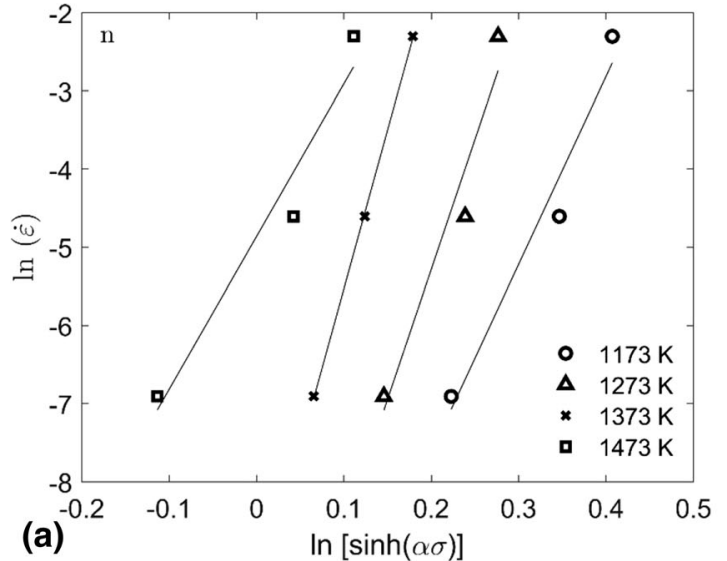

Fig. 9 Relationships between $\ln [\sinh (\alpha \sigma)]$ and (a) $\ln \dot{\varepsilon}$ and (b) $1 / T$

$Q=R\left[\frac{\partial \ln [\sinh (\alpha \sigma)]}{\partial T^{-1}}\right]_{\dot{\varepsilon}}\left[\frac{\partial \ln \dot{\varepsilon}}{\partial \ln [\sinh (\alpha \sigma)]}\right]_{T}$

Therefore, the value of $Q$ can be calculated from the slope of the plot $\ln [\sinh (\alpha \sigma)]$ versus $1 / T$ and the slope of the plot $\ln [\sinh (\alpha \sigma)]$ versus $\ln \dot{\varepsilon}$ as $n$ and $v$ as indicated in Fig. 9(a) and (b). Substituting the values of $\alpha$, forming temperatures, strain rates and corresponding stress under the strain of 0.08 into Eq 17 and utilizing the linear regression via least square method, the value of $n$ is taken as the average of the values under different temperatures, and from Fig. 9(a), it is calculated to be 28.8 .

Using the same method, the average value of the slope of the plot $\ln [\sinh (\alpha \sigma)]$ against $1 / T$, indicated as $v$, is determined to be 1779.86. Since $Q$ is defined as $v n R$ and based on the calculations of the data in Fig. 9(a) and (b), the average value of the activation energy $(Q)$ was found to be $433.66 \mathrm{~kJ} / \mathrm{mol}$.

Function $Z$ can be defined as:

$\ln Z=\ln \dot{\varepsilon}+\frac{Q}{\mathrm{RT}}$

Therefore, Eq 11 can be expressed as follows:

$\ln Z=\ln A+n \ln [\sinh (\alpha \sigma)]$

Figure 10 presents the relationship of $\ln Z$ and $\ln [\sinh (\alpha \sigma)]$. The slope and intercept of the function obtained from linear fitting of this plot, are the value of $n$ and $\ln A$, respectively. $n$ is equal to 29.2 , and $\ln A$ is equal to 30.34 .

After evaluation of $A, n, \alpha$ and $Q$, according to $\mathrm{Eq} 11$, the correlation of peak true stress, temperature and strain rate during hot deformation in MHC alloy under the strain of 0.08 can be expressed as:

$\dot{\varepsilon}=1.5 \times 10^{13}[\sinh (0.00208 \sigma)]^{28.8} \exp \left(-\frac{433.66}{\mathrm{RT}}\right)$

Equation 11 can also be written as:

$\sigma=\frac{1}{\alpha} \ln \left\{\left(\frac{Z}{A}\right)^{\frac{1}{n}}+\left[\left(\frac{Z}{A}\right)^{\frac{2}{n}}+1\right]^{\frac{1}{2}}\right\}$
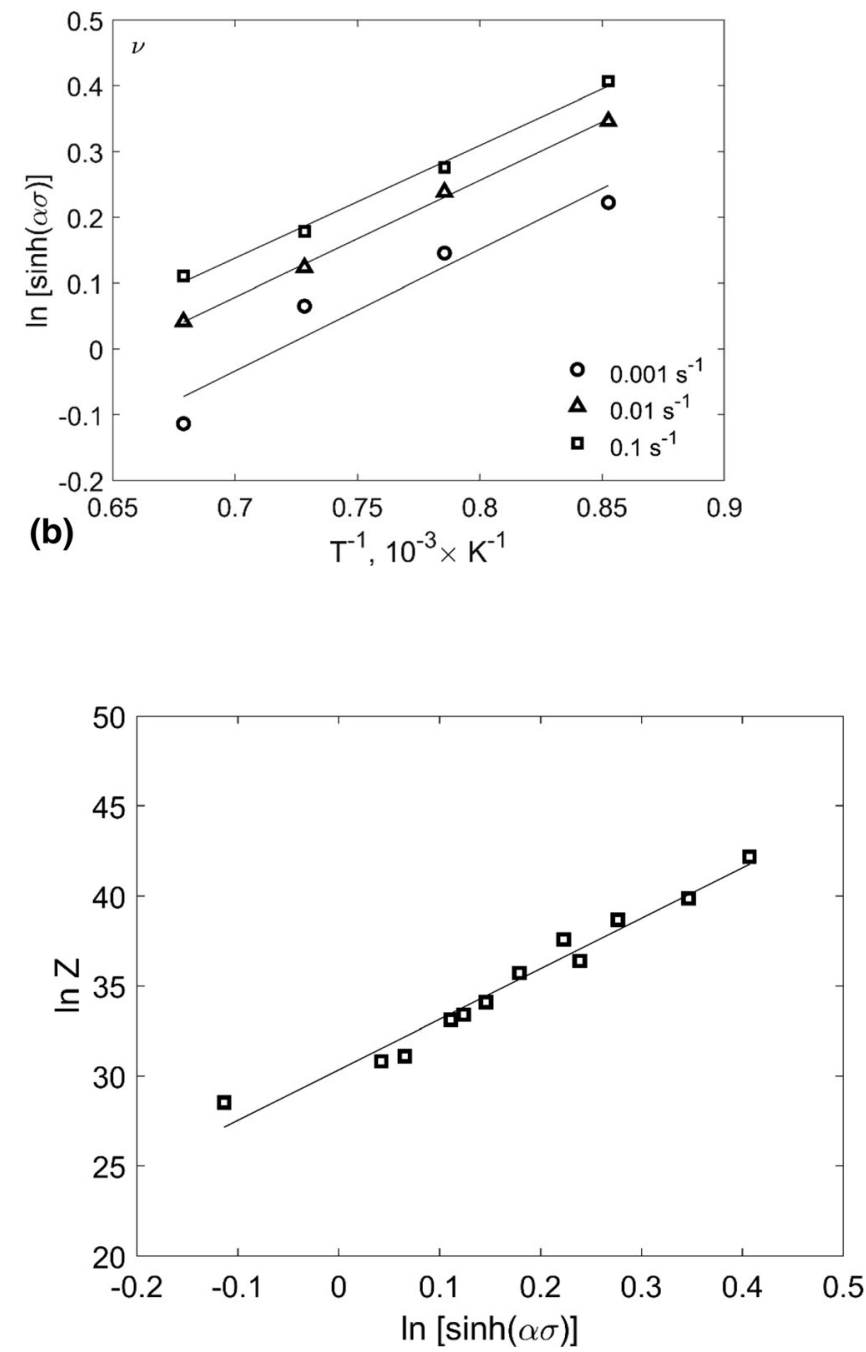

Fig. 10 Relationship between $\ln Z$ and $\ln [\sinh (\alpha \sigma)]$

which relates the flow stress and Zener-Hollomon parameter $Z$.

$Z=\dot{\varepsilon} \exp \left(\frac{\mathrm{Q}}{R T}\right)$

The values of the material constants $(\alpha, n, Q, A)$ of the constitutive equation are calculated for strains of $0.006,0.008$ and 0.01-0.14 with the interval of 0.01. Figure 11(a)-(d) shows the calculated values of the material constants. The fitting results, using the fifth-order polynomial regression functions as a function of true strain are provided in Eq 16-19.

$\alpha=0.002+0.007 \varepsilon-0.12 \varepsilon^{2}+3.382 \varepsilon^{3}-24.245 \varepsilon^{4}+66.65 \varepsilon^{5}$

(Eq 23)

$$
\begin{aligned}
n= & 45.143-288.96 \varepsilon+6.564 \times 10^{3} \varepsilon^{2}-1.452 \times 10^{5} \varepsilon^{3} \\
& +1.225 \times 10^{6} \varepsilon^{4}-3.493 \times 10^{6} \varepsilon^{5}
\end{aligned}
$$



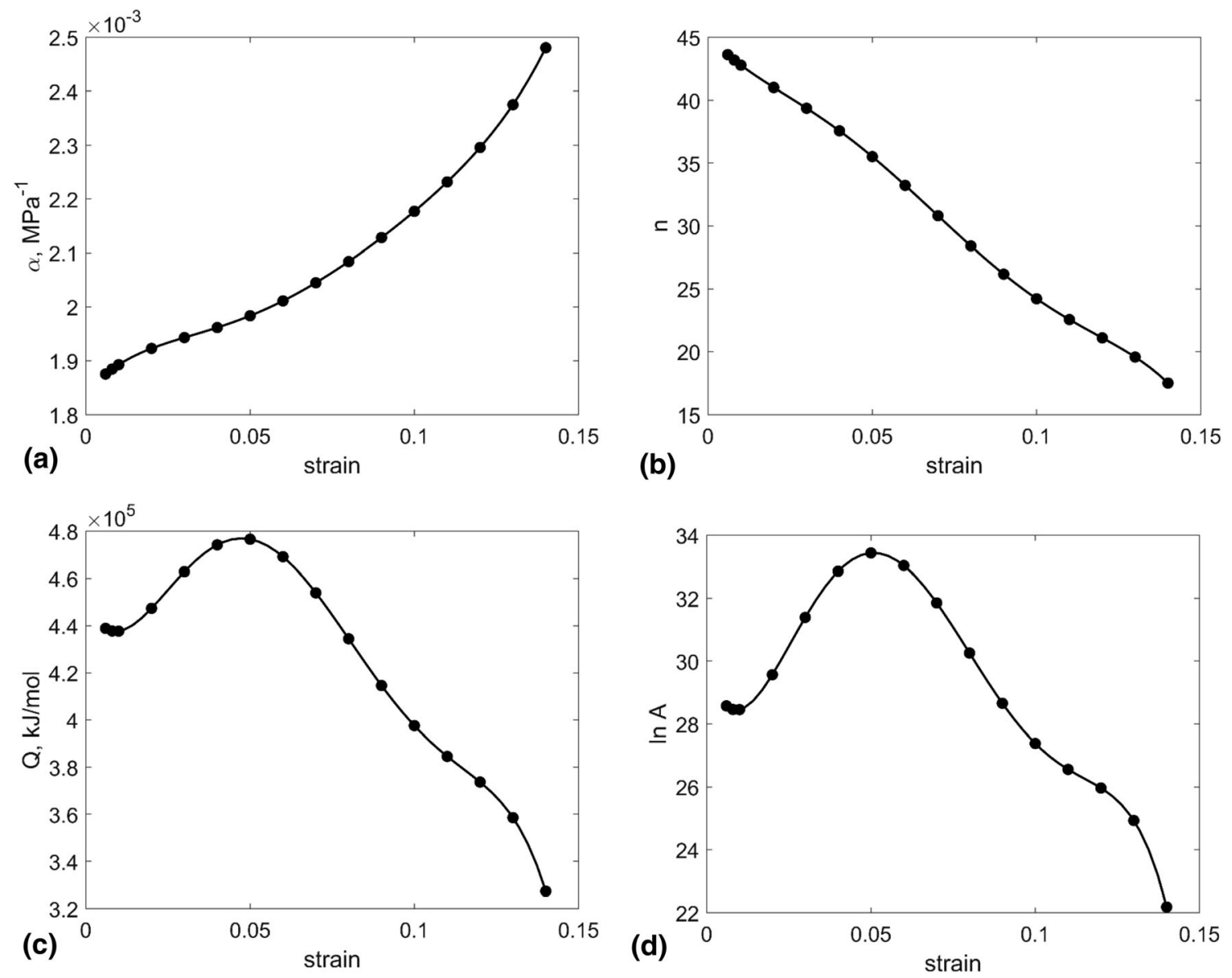

Fig. 11 Variation of (a) $\alpha$, (b) $n$, (c) $Q$ and (d) $\ln A$ with true strain using 5 th polynomial fit

$$
\begin{aligned}
Q= & 4.5 \times 10^{5}-3.08 \times 10^{6} \varepsilon+2.264 \times 10^{8} \varepsilon^{2}-4.657 \\
& \times 10^{9} \varepsilon^{3}+3.64 \times 10^{10} \varepsilon^{4}-9.915 \times 10^{10} \varepsilon^{5}
\end{aligned}
$$

$$
\begin{aligned}
\ln A= & 29.8-335.203 \varepsilon+2.466 \times 10^{4} \varepsilon^{2}-4.97 \times 10^{5} \varepsilon^{3} \\
& +3.871 \times 10^{6} \varepsilon^{4}-1.054 \times 10^{7} \varepsilon^{5}
\end{aligned}
$$

The values of $\alpha, n, \operatorname{LnA}$ and $Q$ are independent of temperature and strain rate at a specific strain.

\section{Constitutive Equations Verification}

The modified Johnson-Cook constitutive Equation 7 and the strain-compensated Arrhenius-type constitutive Equation 21-26 were verified by comparing the experimental and the predicted flow stress values. The comparison between the experimental data and the predicted one from modified Johnson-Cook and Arrhenius-type constitutive equations at several processing conditions is shown in Fig. 12(a)-(d) and 13(a)-(d), respectively. Under most of the conditions, the predicted flow stress values from the Johnson-Cook model could track the experimental values. However, distinct deviations from the experi- mental results can be observed for some conditions, in particular at lower strain rates (i.e. at $1473 \mathrm{~K}$ in 0.001 and $0.01 \mathrm{~s}^{-1}$ and at $1273 \mathrm{~K}$ in $0.001 \mathrm{~s}^{-1}$ ). Li et al. (Ref 14) reported the same observation for the strain rate of $0.01 \mathrm{~s}^{-1}$. On the other hand, the Arrhenius-type constitutive model reveals a better correlation between experimental and predicted values for all deformation conditions, which indicates the excellent capability of the strain-compensated Arrhenius-type constitutive model to predict the flow stress throughout the entire temperature and strain rate range. The difference in the capacity of the two models in predicting the material behaviour could be related the nonlinear flow behaviour of metallic materials at high temperature. Many effective factors on the flow stress are nonlinear, too. Therefore, the effect of the processing parameters on the deformation behaviour can be specified more accurately by Zener-Hollomon parameters in an exponential equation, especially in particular for lower strain rates (Ref 14, 31,32 ).

The predictability of the deformation constitutive equation can be quantified in terms of standard statistical parameters such as average absolute relative error and correlation coefficient which are defined as: (Ref 33)

$R=\frac{\sum_{i=1}^{N}\left(E_{i}-\bar{E}\right)\left(P_{i}-\bar{P}\right)}{\sqrt{\sum_{i=1}^{N}\left(E_{i}-\bar{E}\right)^{2}\left(P_{i}-\bar{P}\right)^{2}}}$ 

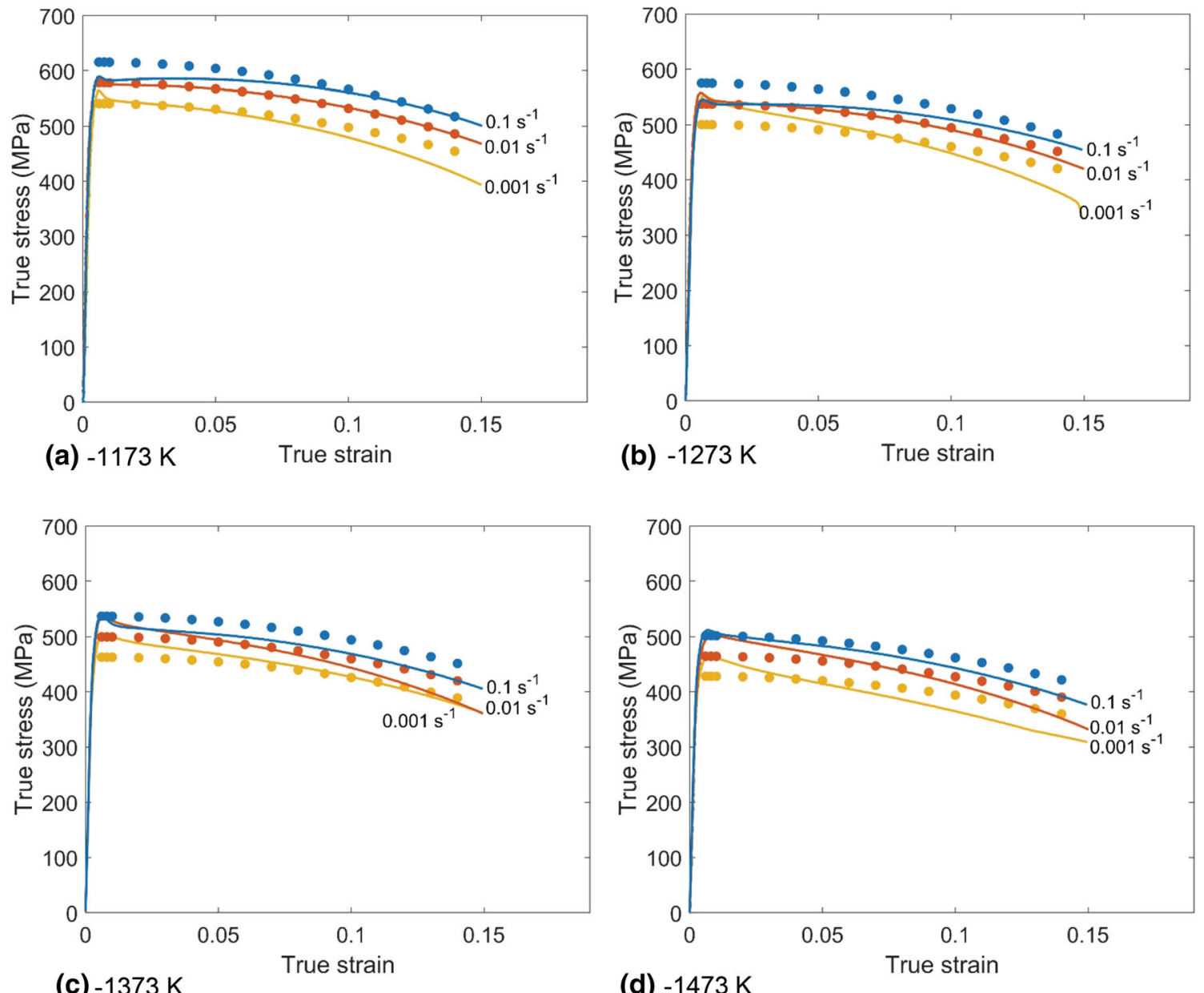

Fig. 12 Comparison of flow stress between experimental data and calculated results by the modified Johnson-Cook constitutive equation at different strain rate and temperature: (a) $1173 \mathrm{~K}$, (b) $1273 \mathrm{~K}$, (c) $1373 \mathrm{~K}$ and (d) $1473 \mathrm{~K}$

$e=\frac{1}{N} \sum_{i=1}^{N}\left|\frac{E_{i}-P_{i}}{E_{i}}\right| \times 100 \%$

where $E$ is experimental flow stress, $P$ is the predicted flow stress, $\bar{E}$ and $\bar{P}$ are the mean values of $E$ and $P$, respectively, $N$ is the total number of evaluated strains. The value of $R$ provides information on the strength of the linear relationship between the experimental and predicted data (Ref 34). The value of $e$ is calculated through a term by term comparison of the relative error and therefore is an unbiased statistical parameter for determining the predictability of the equation (Ref 33 ).

The values of $R$ and $e$ for the total data are calculated and shown in Fig. 14(a) and (b) for the modified Johnson-Cook model and the strain-compensated Arrhenius-type model, respectively. As obvious, the data points for the Arrheniustype model lie much closer to the line than the ones for the modified Johnson-Cook model. The values of $R$ and $e$ are found to be 0.94 and $3.6 \%$ for the Johnson-Cook model and 0.98 and $1.8 \%$ for the Arrhenius-type model. This clearly shows the better correlation between the predicted and experimental data from the Arrhenius-type model.
Figure 15(a) and (b) show the $R$ and $e$ value of the flow stress calculated by the Arrhenius-type model for strains of $0.006,0.008,0.01-0.14$ with an interval of 0.01 , respectively. The curves reveal smaller mean errors values at relatively low temperatures than at high temperatures, which indicates a better agreement at low temperatures. The overall averaged mean error is $1.8 \%$ and the maximum mean error is $3.1 \%$, which appears at the strain rate of $0.001 \mathrm{~s}^{-1}$ and the temperature of $1473 \mathrm{~K}$. However, all mean error values are below 3.5\%. The worst correlation coefficient is 0.987 .

Despite the longer time to evaluate the material constants and the larger number of constants (twice in the Arrhenius-type model), the strain-compensated Arrhenius-type constitutive equation is still favoured compared to the modified JohnsonCook constitutive equation.

\section{Conclusions}

The tensile characteristics of a molybdenum-based refractory alloy have been investigated by means of the uniaxial tensile test over the temperature range between 1173 and 


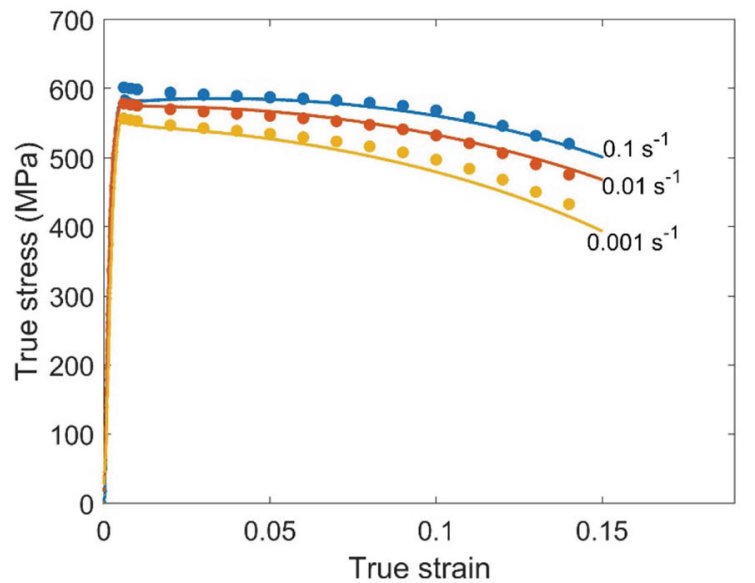

(a) $-1173 \mathrm{~K}$

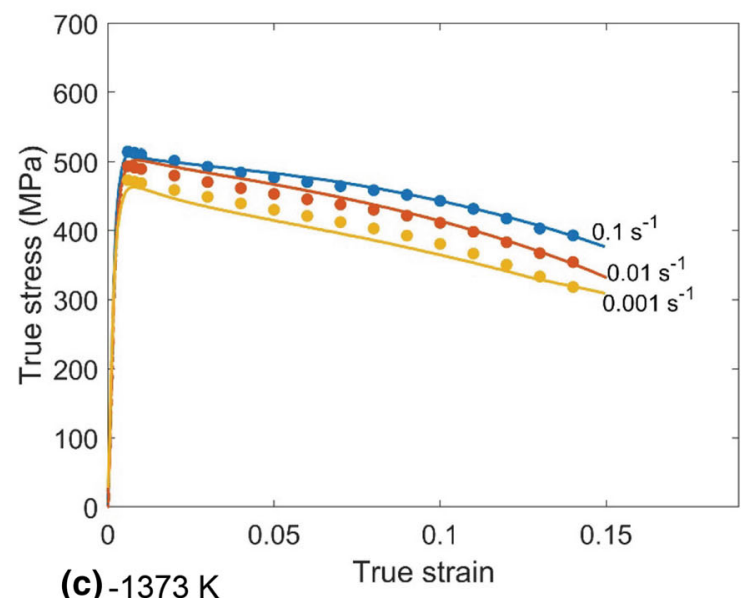

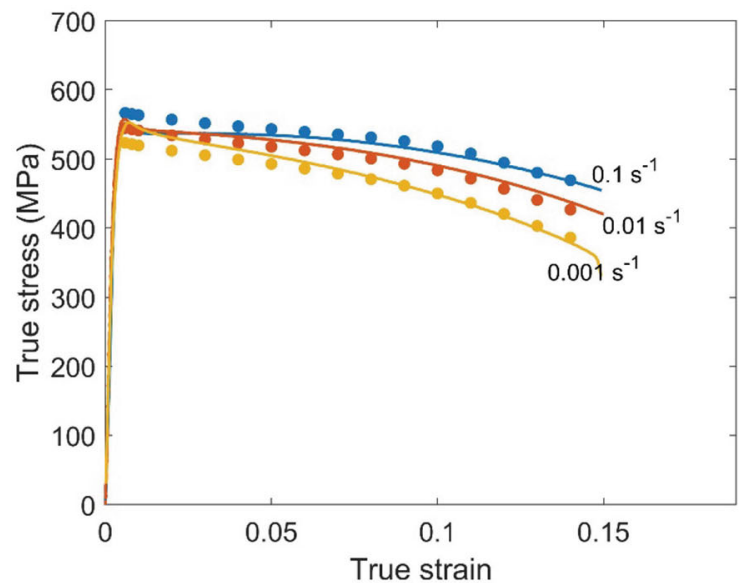

(b) $-1273 \mathrm{~K}$

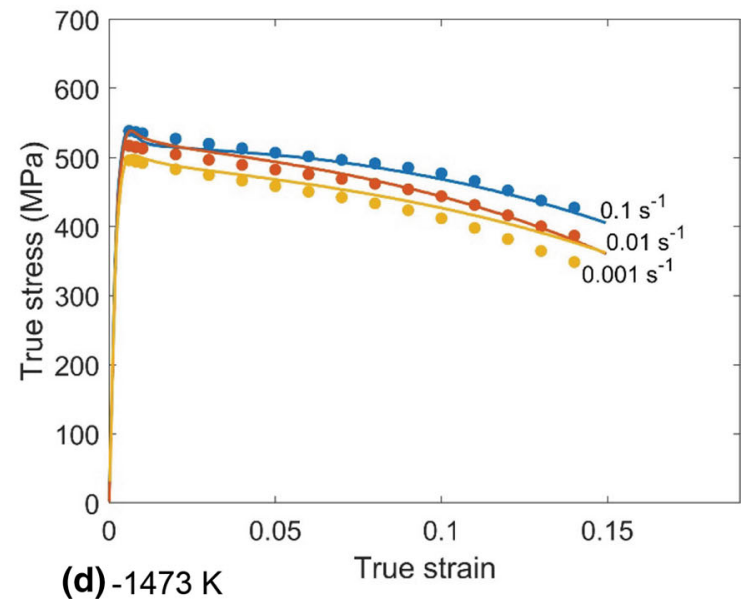

Fig. 13 Comparison of flow stress between experimental data and calculated results by strain-compensated Arrhenius-type equation at different strain rate and temperature: (a) $1173 \mathrm{~K}$, (b) $1273 \mathrm{~K}$, (c) $1373 \mathrm{~K}$ and (d) $1473 \mathrm{~K}$
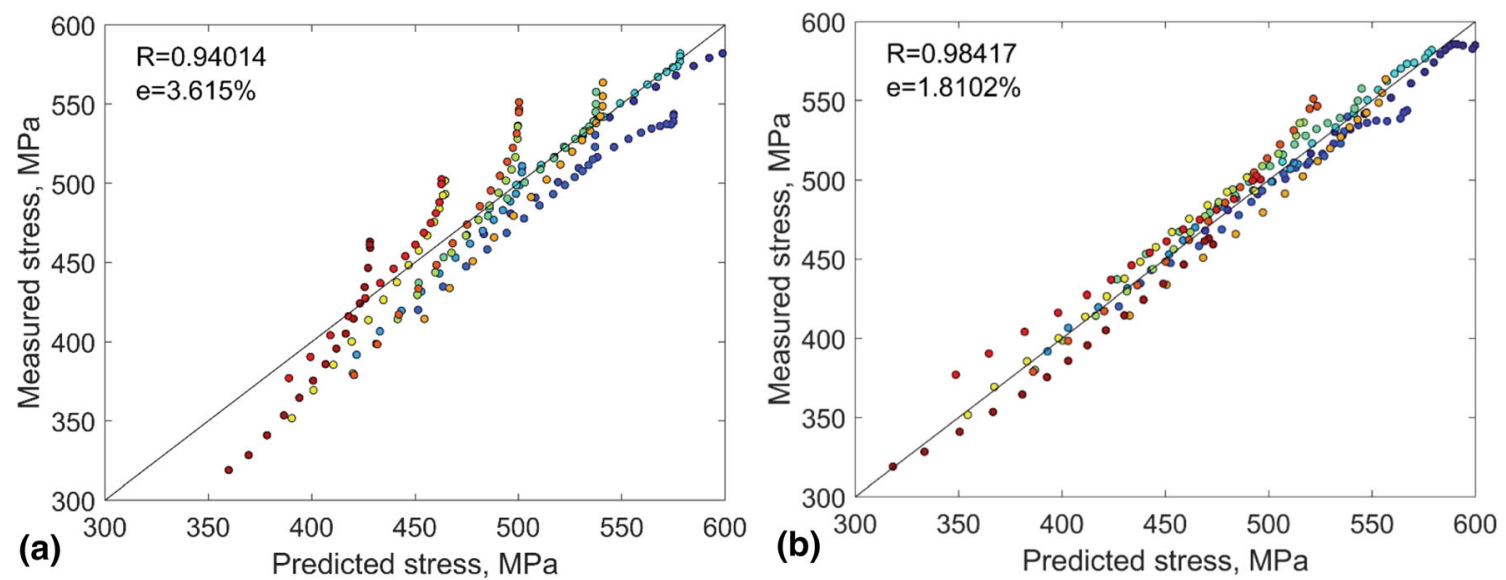

Fig. 14 Correlation between experimental and predicted flow stress data from (a) the modified Johnson-Cook model and (b) the straincompensated Arrhenius-type model

$1473 \mathrm{~K}$ and with strain rate of $0.001,0.01$ and $0.1 \mathrm{~s}^{-1}$. Based on the experimental results, a comparative study was done on the capability of the modified Johnson-Cook and the strain- compensated Arrhenius-type constitutive models to predict the elevated temperature flow behaviour of the MHC alloy. Based on this study, the following conclusions are drawn. 

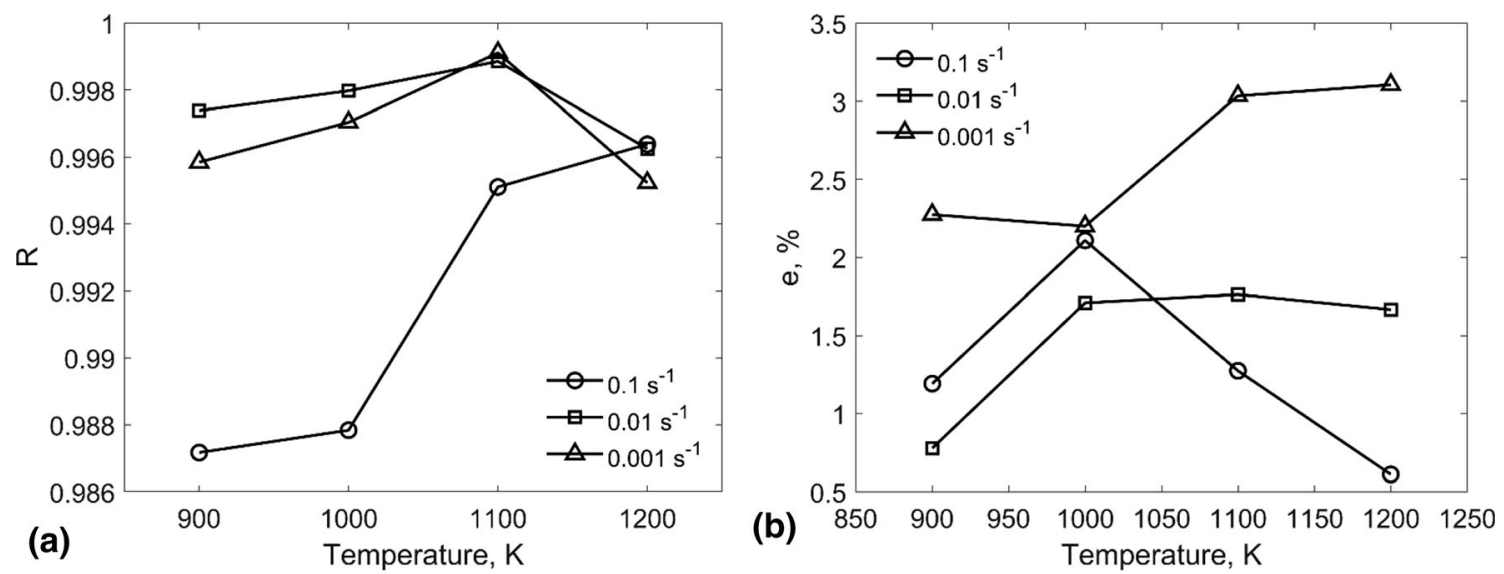

Fig. 15 Values of (a) correlation coefficient, (b) average absolute relative error for strain-compensated Arrhenius-type model under for all experimental conditions

1. The true stress-strain curves of MHC alloy reveal the typical nonlinear behaviour under high-temperature deformation with temperature and strain rate dependency.

2. The modified Johnson-Cook constitutive equation can predict the flow stress for most of the conditions except for lower strain rates. The strain-compensated Arrheniustype constitutive equation can represent the elevated temperature flow behaviour more accurately in the entire processing domain.

3. The average absolute relative errors for the modified Johnson-Cook and the strain-compensated Arrheniustype models are 3.6 and $1.8 \%$, respectively, and the correlation coefficients are 0.98 and 0.94 , correspondingly.

4. Despite the longer evaluation time for the equation constants and the double number of constants for the Arrhenius-type model, the strain-compensated Arrhenius-type constitutive equation is much more reliable in predicting the flow stress values of MHC alloy under above conditions than the modified Johnson-Cook constitutive equation.

\section{Acknowledgments}

The present work is financially supported by the Graduate Research School Cluster LokPro, Brandenburg Technical University, Germany. Mr. M. Günther is warmly thanked for his technical support.

\section{Funding}

Open Access funding enabled and organized by Projekt DEAL.

\section{Open Access}

This article is licensed under a Creative Commons Attribution 4.0 International License, which permits use, sharing, adaptation, distribution and reproduction in any medium or format, as long as you give appropriate credit to the original author(s) and the source, provide a link to the Creative Commons licence, and indicate if changes were made. The images or other third party material in this article are included in the article's Creative Commons licence, unless indicated otherwise in a credit line to the material. If material is not included in the article's Creative Commons licence and your intended use is not permitted by statutory regulation or exceeds the permitted use, you will need to obtain permission directly from the copyright holder. To view a copy of this licence, visit http://creativecommons.org/licenses/by/4.0/.

\section{References}

1. J.H. Perepezko, Materials Science: the Hotter the Engine, the Better, Science, 2009, 326(5956), p 1068-1069. https://doi.org/10.1126/scie nce. 1179327

2. M.S. El-Genk and J.-M. Tournier, A Review of Refractory Metal Alloys and Mechanically Alloyed-Oxide Dispersion Strengthened Steels for Space Nuclear Power Systems, J. Nucl. Mater, 2005, 340(1), p 93-112. https://doi.org/10.1016/j.jnucmat.2004.10.118

3. K.S. Shin, D.L. Jacobson, L. D'cruz, A. Luo; B.-L. Chen, et al. HighTemperature Alloys for High-Power Thermionic Systems. No. DOE/ SF/17170-T25. Arizona State University, Tempe, AZ (USA). Department of Chemical, Bio and Materials Science Engineering, 1990

4. C. Pöhl, D. Lang, J. Schatte and H. Leitner, Strain Induced Decomposition and Precipitation of Carbides in a MolybdenumHafnium-Carbon Alloy, J. Alloys Compd., 2013, 579, p 422-431. h ttps://doi.org/10.1016/j.jallcom.2013.06.086

5. Y. Luo, H. Guo, J. Guo and W. Yang, Gleeble-Simulated and SemiIndustrial Studies on the Microstructure Evolution of Fe-Co-Cr-Mo-WV-C Alloy During Hot Deformation, Materials (Basel, Switzerland), 2018, 11(12), p 2577. https://doi.org/10.3390/ma11122577

6. S. Majumdar, R. Kapoor, S. Raveendra, H. Sinha, I. Samajdar, P. Bhargava et al., A Study of Hot Deformation Behaviour and Microstructural Characterization of Mo-TZM Alloy, J. Nucl. Mater, 2009, 385(3), p 545-551. https://doi.org/10.1016/j.jnucmat.2008.12.0 49

7. A. Chaudhuri, A. Sarkar and S. Suwas, Investigation of Stress-Strain Response, Microstructure and Texture of Hot Deformed Pure Molybdenum, Int. J. Refract. Met. Hard Mater., 2018, 73, p 168-182. h ttps://doi.org/10.1016/j.ijrmhm.2018.02.011

8. S. Primig, H. Leitner, W. Knabl, A. Lorich, H. Clemens and R. Stickler, Textural Evolution During Dynamic Recovery and Static Recrystallization of Molybdenum, Metall. Mat. Trans. A, 2012, 43(12), p 4794 4805. https://doi.org/10.1007/s11661-012-1291-5

9. A. Chaudhuri, A.N. Behera, A. Sarkar, R. Kapoor, R.K. Ray and S. Suwas, Hot Deformation Behaviour of Mo-TZM and Understanding the Restoration Processes Involved, Acta Mater, 2019, 164, p 153164. https://doi.org/10.1016/j.actamat.2018.10.037

10. Y. Xia, P. Hu, K.-S. Wang, S.-L. Li, H.-R. Xing, T. Chang et al., Microstructure and texture evolution of pure molybdenum during hot deformation, Mater. Charact., 2020, 159, p 110010. https://doi.org/10. 1016/j.matchar.2019.110010 
11. A.-Q. Wang, H.-D. Guo, Y.-P. Ju, J.-P. Xie and Y.-F. Cheng, Hot Deformation Behaviour of Pure Molybdenum (Mo), Sci. Adv. Mater. 2017, 9(9), p 1493-1500. https://doi.org/10.1166/sam.2017.3188

12. F. Fang, Y.Y. Zhou and W. Yang, In-situ SEM Study of Temperature Dependent Tensile Behaviour of Wrought Molybdenum, Int. J. Refract. Met. Hard Mater., 2013, 41, p 35-40. https://doi.org/10.1016/j.ijrmhm. 2013.01.014

13. A.P. Alur, N. Chollacoop and K.S. Kumar, High-Temperature Compression Behaviour of Mo-Si-B Alloys, Acta Mater, 2004, 52(19), p 5571-5587. https://doi.org/10.1016/j.actamat.2004.08.035

14. H.-Y. Li, Y.-H. Li, X.-F. Wang, J.-J. Liu and Y. Wu, A Comparative Study on Modified Johnson Cook, Modified Zerilli-Armstrong and Arrhenius-Type Constitutive Models to Predict the Hot Deformation Behaviour in 28CrMnMoV Steel, Mater. Des., 2013, 49, p 493-501. h ttps://doi.org/10.1016/j.matdes.2012.12.083

15. M. Xiao, F. Li, H. Xie and Y. Wang, Characterization of Strengthening Mechanism and Hot Deformation Behaviour of Powder Metallurgy Molybdenum, Mater. Des., 2012, 34, p 112-119. https://doi.org/10. 1016/j.matdes.2011.07.065

16. S. Krishna and S. De, A Temperature and Rate-Dependent Micromechanical Model of Molybdenum Under Neutron Irradiation, Mech. Mater, 2011, 43(2), p 99-110. https://doi.org/10.1016/j.mechmat.2010. 12.005

17. C. Chen, H. Yin, I.S. Humail, Y. Wang and X. Qu, A Comparative Study of a Back Propagation Artificial Neural Network and a ZerilliArmstrong Model for Pure Molybdenum During Hot Deformation, Int J. Refract. Met. Hard Mater., 2007, 25(5-6), p 411-416. https://doi.org/ 10.1016/j.ijrmhm.2006.11.004

18. A. He, G. Xie, H. Zhang and W. Xitao, A Comparative Study on Johnson-Cook, Modified Johnson-Cook and Arrhenius-Type Constitutive Models to Predict the High Temperature Flow Stress in $20 \mathrm{CrMo}$ Alloy Steel, Mater. Des., 2013, 52, p 677-685. https://doi.org/10.1016/ j.matdes.2013.06.010

19. D. Samantaray, S. Mandal and A.K. Bhaduri, A Comparative Study on Johnson Cook, Modified Zerilli-Armstrong and Arrhenius-Type Constitutive Models to Predict Elevated Temperature Flow Behaviour in Modified 9Cr-1Mo Steel, Comput. Mater. Sci., 2009, 47, p 568-576. h ttps://doi.org/10.1016/j.commatsci.2009.09.025

20. J. Cheng, S. Nemat-Nasser and W. Guo, A Unified Constitutive Model for Strain-Rate and Temperature Dependent Behaviour of Molybdenum, Mech. Mater, 2001, 33(11), p 603-616. https://doi.org/10.1016/ S0167-6636(01)00076-X

21. C. Schimpf, T. Mrotzek and U. Martin, Thermally Activated Flow Stress Component of the Mo Alloy TZM Determined by Constitutive Models, Int. J. Refract. Met. Hard Mater, 2010, 28(6), p 716-721. h ttps://doi.org/10.1016/j.ijrmhm.2010.04.008

22. B. Meng, M. Wan, X. Wu, Y. Zhou and C. Chang, Constitutive Modeling for High-Temperature Tensile Deformation Behaviour of Pure Molybdenum Considering Strain Effects, Int. J. Refract. Met. Hard Mater, 2014, 45, p 41-47. https://doi.org/10.1016/j.ijrmhm.2014. 03.005

23. C.M. Sellars and W.J. McTegart, On the mechanism of hot deformation, Acta Metall., 1966, 14, p 1136-1138
24. Y.C. Lin, X.-M. Chen and G. Liu, A Modified Johnson-Cook Model for Tensile Behaviours of Typical High-Strength Alloy Steel, Mater. Sci. Eng. A, 2010, 527(26), p 6980-6986. https://doi.org/10.1016/j. msea.2010.07.061

25. S. Primig, H. Leitner, H. Clemens, A. Lorich, W. Knabl and R. Stickler, On the Recrystallization Behaviour of Technically Pure Molybdenum, Int. J. Refract. Met. Hard Mater., 2010, 28(6), p 703-708. https://doi. org/10.1016/j.ijrmhm.2010.03.006

26. S. Bruschi, S. Poggio, F. Quadrini and M.E. Tata, Workability of Ti6Al-4V Alloy at High Temperatures and Strain Rates, Mater. Lett., 2004, 58(27-28), p 3622-3629. https://doi.org/10.1016/j.matlet.2004. 06.058

27. J. Luo, M. Li, H. Li and W. Yu, Effect of the Strain on the Deformation Behaviour of Isothermally Compressed Ti-6Al-4V alloy, Mater. Sci. Eng. A, 2009, 505(1-2), p 88-95. https://doi.org/10.1016/j.msea.2008. 11.001

28. B. Li, Q. Pan and Z. Yin, Microstructural Evolution and Constitutive Relationship of Al-Zn-Mg Alloy Containing Small Amount of Sc and Zr During Hot Deformation Based on Arrhenius-Type and Artificial Neural Network Models, J. Alloys Compd., 2014, 584, p 406-416. h ttps://doi.org/10.1016/j.jallcom.2013.09.036

29. Z. Fan, X. Lin, Y. Dong, R. Xu, C. Li and N. Liu, Constitutive Model and Deformation Microstructure of Fine-Grain Mg-Zn-Y Alloy Solidified Under High Pressure, J. Rare Earths, 2016, 34(9), p 945-951. h ttps://doi.org/10.1016/S1002-0721(16)60119-9

30. X. Yang, W. Li, J. Ma, S. Hu, Y. He, L. Li and B. Xiao, ThermoPhysical Simulation of the Compression Testing for Constitutive Modeling of GH4169 Superalloy During Linear Friction Welding, $J$. Alloys Compd., 2016, 656, p 395-407. https://doi.org/10.1016/j.jallc om.2015.09.267

31. J. Cai, K. Wang, P. Zhai, F. Li and J. Yang, A Modified Johnson-Cook Constitutive Equation to Predict Hot Deformation Behaviour of Ti6Al-4V Alloy, Int. J. Mater. Eng. Perform., 2015, 24(1), p 32-44. h ttps://doi.org/10.1007/s11665-014-1243-x

32. Y.C. Lin and X.-M. Chen, A Critical Review of Experimental Results and Constitutive Descriptions for Metals and Alloys in Hot Working, Mater. Des., 2011, 32(4), p 1733-1759. https://doi.org/10.1016/j.matde s.2010.11.048

33. S. Mandal, P.V. Sivaprasad, S. Venugopal and K.P.N. Murthy, Artificial Neural Network Modeling to Evaluate and Predict the Deformation Behaviour of Stainless Steel Type AISI 304L During Hot Torsion, Appl. Soft Comput., 2009, 9(1), p 237-244. https://doi.org/10.1016/j.a soc.2008.03.016

34. M.R. Rokni, A. Zarei-Hanzaki, A.A. Roostaei and A. Abolhasani, Constitutive Base Analysis of a 7075 Aluminum Alloy During Hot Compression Testing, Mater. Des., 2011, 32(10), p 4955-4960. http s://doi.org/10.1016/j.matdes.2011.05.040

Publisher's Note Springer Nature remains neutral with regard to jurisdictional claims in published maps and institutional affiliations. 